\title{
Aerodynamics and Flow Characteristics of X-45 Delta Wing Planform
}

\author{
Bulent YANIKTEPE ${ }^{1 *}$, Coskun OZALP ${ }^{2}$, Cetin CANPOLAT ${ }^{3}$ \\ ${ }^{1}$ Department of Energy Systems Engineering, Faculty of Engineering, Korkut Ata University, Osmaniye, 80000, \\ Turkey \\ ${ }^{2}$ Department of Energy Systems Engineering, Faculty of Engineering, Korkut Ata University, Osmaniye, 80000, \\ Turkey \\ ${ }^{2}$ Department of Biomedical Engineering, Faculty of Engineering and Architecture, Cukurova University, Adana, \\ 01330, Turkey
}

\begin{abstract}
The present experimental work investigates the near surface flow structure and aerodynamic characteristics of X-45 type non-slender delta wing planform using dye visualization, Stereoscopic Particle Image Velocimetry (stereo-PIV) and aerodynamic load measurements. The instantaneous images are acquired on the planview plane within $5^{\circ} \leq \alpha \leq 20^{\circ}$ to calculate the time-averaged flow data. In order to compare flow structures with other non-slender wing planforms such as delta and lambda, previously presented dye visualization and stereo-PIV results are also provided. It can be concluded that vortical flow with a pair of well-defined LEVs over X-45 develop at very low angles of attack, and form close to the wing surface similar to delta and lambda planforms. The stall occurs at an angle of attack $\alpha=32^{\circ}$, whereas stalling is evident at relatively lower angles of attack for simple delta wing.
\end{abstract}

Keywords: Aerodynamics, delta wing, stereo-PIV, X-45

\section{X-45 Tipi Delta Kanat Modeli Üzerinde Oluşan Akış Karakteristikleri ve Aerodinamiği}

ÖZET: Mevcut deneysel çalışma ile X-45 tipi delta kanat modeli üzerinde oluşan yakın yüzey akış yapısı ve aerodinamik karakteristikleri, boya görüntüleme, üç boyutlu Stereoskopik Parçacık Görüntüleme Tekniği (stereo PIV) ve aerodinamik kuvvet ölçümleri kullanılarak araştırılmıştır. Anlık görüntüler ile üst görünüş düzleminde zaman ortalama akış verileri $5^{\circ} \leq \alpha \leq 20^{\circ}$ hücum açılarında elde edilmiştir. Delta ve Lamda tipi diğer düşük süpürme açılarına sahip delta kanat modelleri ile akıș yapılarını karşılaştırmak için önceki sunulan boya görüntüleri ve steroPIV sonuçları kullanılmıştır. Düşük hücum açılarında X-45 tipi delta kanat modeli üzerinde iyi tanımlanmış ön uç yanal girdaplar delta ve lamda modellerine benzer kanat yüzeyinde oluşmaktadır. X-45 tipi delta kanat modelinde ölü akış yapısı $\alpha=32^{\circ}$ de oluşmaktayken basit delta kanat ve lamda modellerinde daha düşük hücum açılarında meydana gelmektedir.

Keywords: Aerodinamik, delta kanat, stereo-PIV, X-45

\section{INTRODUCTION}

Delta planform is an essential aerodynamic configuration, which could be effectively used at relatively high angles of attack than conventional wings in subsonic flow conditions. High structural strength and lift are the other features of the delta wings, which have been employed for various missions, especially in combat aerial vehicles [1]. The flow over delta wings can be characterized by a pair of leading edge vortices emanating from wing apex [2]. Boundary layer separation causes these vortical structures formed by rolling up of viscous flow sheet. This flow separation mechanism is occurred due to angle of attack and sharp leading edges of the delta wing [3-4]. These vortices could not maintain their strength along their central axes and vortex breakdown is occurred at a certain distance from delta wing apex when angle of attack is

increased slightly [5]. Benefits procured by delta wing configurations in maneuverability and structural strength increase importance and utilization of this type of planforms for both social and combat missions. Therefore, complexity and variety in planform designs rise to catch the best under abnormal flow conditions. Recently, researchers focus on more specialized wing planforms than simple ones.

The formation of vortex breakdown over the delta wing planforms has strong influence on wing aerodynamics in such a way that lift and drag forces decrease or increase depending on its spatial location from the wing apex [6]. Locations and unsteady structure of the vortex breakdown are investigated by [7] using the spectral analysis and statistical analysis. It was found that there is a strong interaction between 
vortex breakdown and delta wing planform. In order to determine results of this interaction, the near surface topology of a generic delta wing is investigated by [8] by utilizing two dimensional particle image velocimetry. Moreover, [9] and [10] also perform measurements close to the surface of different delta wings using stereoscopic particle image velocimetry. They conclude that flow topology and corresponding unsteady flow features are directly influenced with angle of attack, $\alpha$ which defines the location of vortex breakdown. In addition, yaw angle, $\theta$ is also crucial parameter affecting vortex breakdown location. Altitude loss of airplane on air (stall) is concerned by increasing angle of attack. Knowledge about the aerodynamic properties of the delta wing in unsteady motion is vitally important in applications. The unsteady flow region expanded velocity values and turbulent fluctuation levels rapidly changed in this region. Yaniktepe and Rockwell [11], who defined the distributions of time-averaged velocity vectors and streamlines using the PIV technique, presented that the vortex breakdown beginning from the wing apex occurred much more explicitly at high angle of attacks for the delta wing with sweep angle values of $\Lambda \leq 40^{\circ}$. [12] performed experiments using dye visualization and PIV for Boeing X-45A UCAV configuration to determine the flow structure and its Reynolds number dependence. It is concluded that vortex breakdown occur at relatively low angles of attack, which is the common feature of all non-slender wing models, and its location move in upstream direction substantially.

Aerodynamic coefficients including lift and drag are very crucial in design process of the wings. Because they are utilized for development and implementation of control systems, in order to maintain aircraft stability against abrupt changes. Slender wings are studied for years and aerodynamic

\section{EXPERIMENTAL ARRANGEMENTS AND TECHNIQUES}

Experiments were conducted in the circulating free-surface water channel which was equipped with $15 \mathrm{~kW}$ centrifugal pump and its speed control unit to drive water throughout the channel. The internal dimensions of the water channel which was made of $15 \mathrm{~mm}$ thick transparent Plexiglas sheet with upstream and downstream fiberglass reservoirs were of $8000 \mathrm{~mm} \times 1000 \mathrm{~mm} \times 750 \mathrm{~mm}$. In order to obtain uniform flow conditions, the water was pumped into a settling chamber, passed through a honeycomb coefficients are almost known for different flow conditions and wing planforms. However, aerodynamic characteristics of non-slender wings are rarely found in the literature. They have lower maximum lift coefficient with lower stall angle than slender wings [1]. [13] determined lift and drag coefficients of UCAV 1303 model, which is built on a lambda planform under various magnitudes of angle of attack and yaw angle. This wing model is also characterized by numerous studies [14-15]. [16] also carried out experiments for lambda wing configuration with sweep angle of $\Lambda=40^{\circ}$. They concluded that maximum buffeting occurs near trailing edge region for the angles of attack greater than $\alpha=10^{\circ}$. Recently, [17] present the aerodynamic characteristics of lambda wing close to the surface using the tool of computational fluid dynamics for different flight conditions.

The current study aims at revealing the effects of angle of attack on the flow structure over delta wing planform named as X-45 using dye visualization and stereoscopic particle image velocimetry (stereo-PIV) techniques. In order to relate flow structure with aerodynamics characteristics, variations of lift and drag coefficients with angle of attack are plotted. The angle of attack is varied within $5^{\circ} \leq \alpha \leq 35^{\circ}$ for $\mathrm{X}-45$ wing planform. Flow over two different wing planforms, called as delta and lambda with the variation of angle of attack within $7^{\circ} \leq \alpha \leq 17^{\circ}$ are also presented to demonstrate the distinctions of flow characteristics of X-45. Reynolds number is kept constant at $\mathrm{Re}=10.000$ for all experiments. The sweep angle of the wings is specified as $\Lambda=40^{\circ}$. In addition to dye visualization experiments, unsteady flow structure under the delta wing planforms are observed using time-averaged parameters, such as vector field, $<\mathrm{V}\rangle$ and vorticity, $\langle\omega\rangle$ obtained from the PIV experiments.

section and a two-to-one channel contraction before reaching the test chamber. The delta wing had a chord length of $C=168 \mathrm{~mm}$ with a sweep angle of $\Lambda=40^{\circ}$ for the experiments. The schematic of experimental arrangement was presented in Fig. 1a and 1b.The depth of the water in the test section was adjusted to $530 \mathrm{~mm}$ for the present experiments. Reynolds number, $\mathrm{Re}_{\mathrm{c}}$ based on the delta wing chord length was kept constant for all experiments as $\operatorname{Re}_{\mathrm{c}}=10000$ which corresponds to the free-stream velocity of $56 \mathrm{~mm} / \mathrm{s}$. 


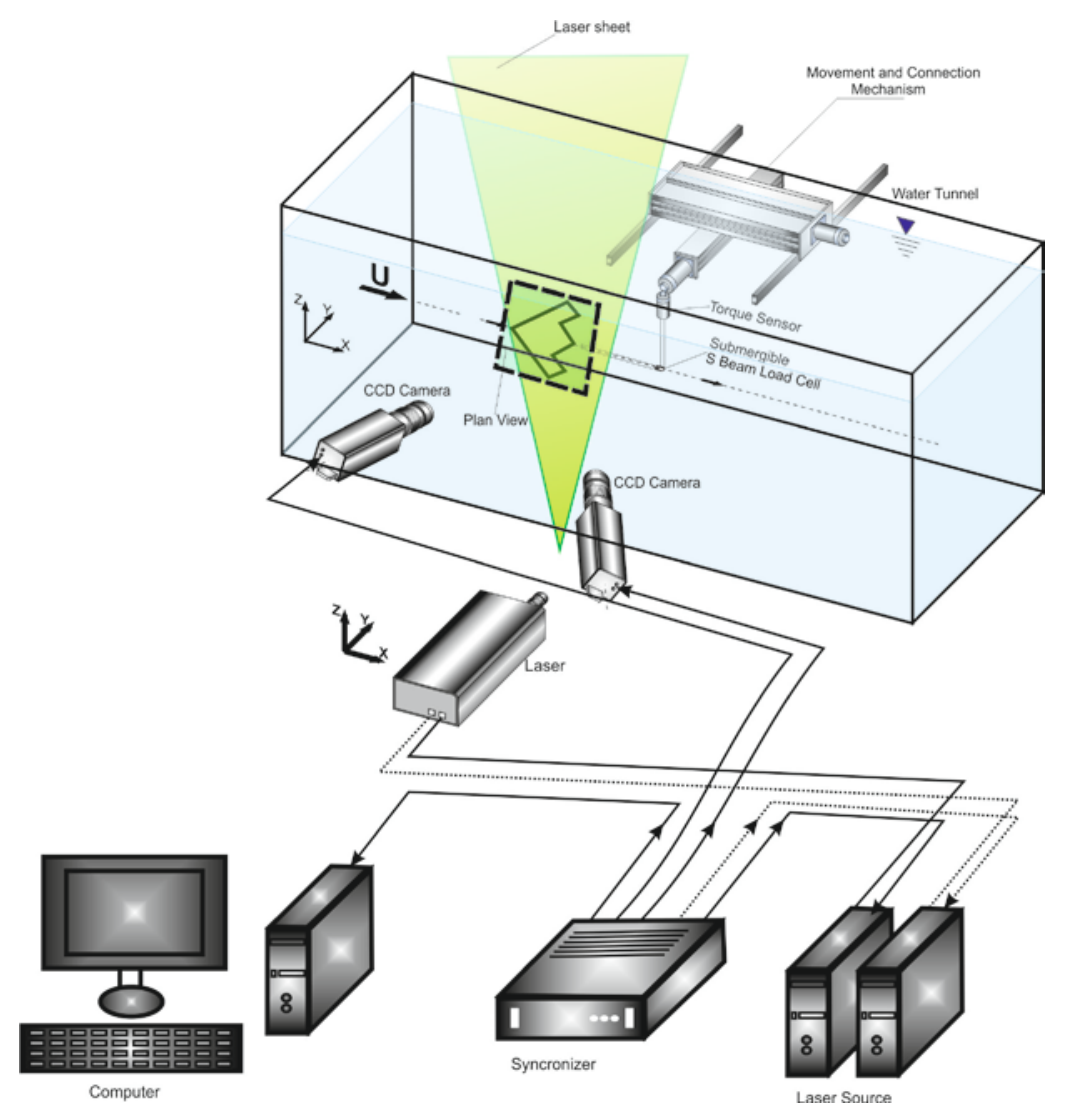

Figure 1a. Schematic representation of PIV experimental set-up in water tunnel

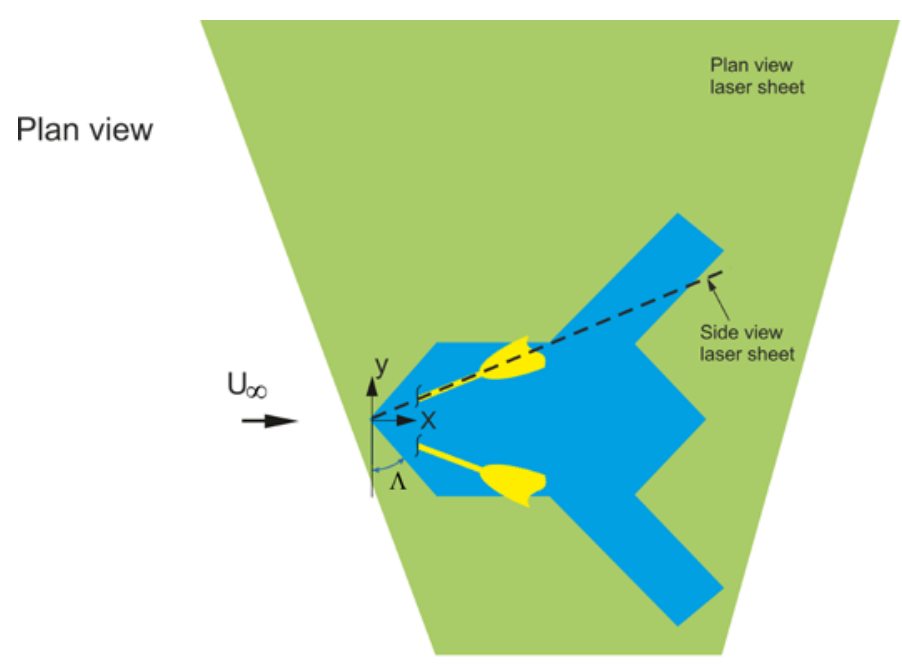

Side view

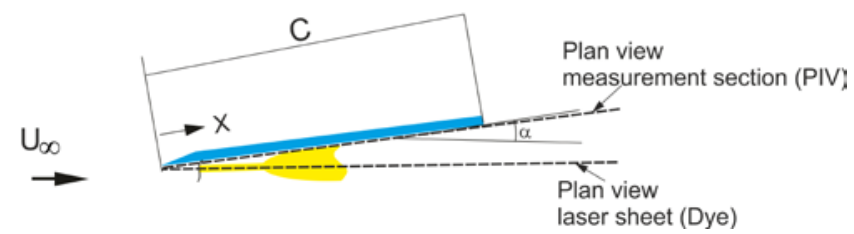

Fig.1b. Experimental arrangements and instrumentation showing crucial parameters and wing model. 
A fluorescent dye which shines under the laser sheet was used to create color change in the water to visualize flow characteristics over the delta wing during dye experiments. Dye was injected to the near field of the delta wing trailing edge by a plastic pipe and dye was passed through a narrow and closed channel along the chord of the delta wing to its apex. The video camera (SONY HD-SR1) was used to capture the instantaneous video images of the vortex flow structures. For the present dye visualization, the flow characteristics over the delta wing in the sideview and plan-view planes were demonstrated with the variations in angle of attack, $\alpha$.

Instantaneous velocity vectors were measured in a region illuminated by a two-dimensional laser sheet using the stereoscopic particle image velocimetry (stereo-PIV) technique which allowed performing three component measurements on two dimensional plane. Emphasis on this technique was the capability of looking at the measuring plane by two cameras with same angle from the horizontal plane based on the principle of stereoscopic imaging, which was same with the human eyesight. All stereoscopic systems having configuration variety have to provide two simultaneous; however, different views of same object as [18] reported. The two views were then combined using one of an assortment of algorithms to reconstruct the three-dimensional field. The detailed information about Stereoscopic PIV could be obtained from [19-22]. The water was seeded with neutrally buoyant silver-coated spherical glass particles, $12 \mu \mathrm{m}$ in diameter to observe the fluid motion. The measurement plane was illuminated with a maximum laser energy output of $120 \mathrm{~mJ} /$ pulse. The time interval between pulses was $1.5 \mathrm{~ms}$ for all measurements.

The thickness of the laser sheet illuminating the measuring plane was approximately $1.5 \mathrm{~mm}$. The time interval and the laser sheet thickness were selected when the maximum particle displacements in the interrogation window were obtained. Velocity vector measurements were performed by Dantec PIV system. The flow field illumination was provided by two Nd:Yag pulsed laser sources of a wavelength of 532 $\mathrm{nm}$ with a maximum energy output of $120 \mathrm{~mJ}$. Dantec Flow Map Processor which controlled the timing of the data acquisition was used for synchronizing the camera and laser units. The movements of the particles were recorded using a CCD camera with a resolution of $1600 \times 1186$ pixels. The camera was equipped with a $60 \mathrm{~mm}$ focal-length lens. Totally 900 instantaneous images were taken, with an acquisition frequency of $15 \mathrm{~Hz}$ for each continuous run. Dantec digital PIV software employing frame-to-frame adaptive correlation technique was used to calculate the raw displacement vector field from instantaneous images of measuring field. In the image processing, 32 x 32 pixels with rectangular effective interrogation windows providing $7227(99 \times 73)$ velocity vectors over the entire field of view plane was used. During the interrogation process, an overlap of $50 \%$ was employed. For the present investigation, the PIV experiments were conducted within $5^{\circ} \leq \alpha \leq 25^{\circ}$.

Comprehensive load and moment measurements were conducted for steady and unsteady flow conditions. A force measurement system, which includes a sensitive Submergible S Beam Junior Load Cell (FUTEK Model LSB 210) and two torque sensors (TFF400) was designed and built specifically for the use of water tunnel. Maximum capacities of the load cell and torque sensor were $100 \mathrm{gr}$ and $0.04 \mathrm{Nm}$, respectively. Moreover, nonlinearities of load cell and torque sensor are also $\pm 3 \%$ and $\pm 1 \%$, respectively. The force measurement systems were capable of measuring the lift force (FL), drag force (FD) and pitching moment (PM) for stationary and pitching cases of the wing.

\section{RESULTS AND DISCUSSIONS}

Formation of the vortical flow structure over the nonslender delta, lambda and X-45 wings are presented under different angles of attack, $\alpha$ conditions in Fig.2a. Vortical flow over the wings develop at very low angles of attack, and form close to the wing surface as also indicated by [1]. However, the leading edge vortices (LEVs) take place further away from the surface of the slender delta wing compared to the present wings [23-24]. A pair of well-defined LEVs is obviously identifiable at $\alpha=7^{\circ}$ and $10^{\circ}$ for the delta wing. In contrast, these vortices are identifiable only at $\alpha=7^{\circ}$ for the lambda wing and at $\alpha=5^{\circ}$ for the $X-45$ wing. In other words, structure of a pair of leading edge vortices loses their coherency when the angle of attack is $\alpha \geq 10^{\circ}$ for $\mathrm{X}-45$ and lambda wing, whereas same case can be pronounced when angle of attack is $\alpha \geq 13^{\circ}$ for the delta wing. The location of vortex breakdown moves to the apex of all wing planforms when the angle of attack, $\alpha$ increases slightly [4].

In addition, spatial location of the vortex breakdown from the wing apex takes its lowest value for X-45, when the vortex breakdown is observed. Wings produce separation vortices like submerged obstacles in the flow field after a certain value of angle of attack, $\alpha$ as seen in Fig.2a.

High scale Kelvin-Helmholtz vortex structures occur at the bottom of the unstable flow region, especially for the attack angles of $\alpha=13^{\circ}$ and $17^{\circ}$ for delta and lambda planforms. However, this is not the case for X-45 due to the close formation of the LEVs to the wing surface and their strength. In order to observe LEV formation over the X-45 wing planform 
in high angle of attack conditions similar to the slender wings, the cases of $\alpha=30^{\circ}$ and $35^{\circ}$ are presented in Fig. 2b. In contrast to the case of slender wings, vertical extent of the leading edge vortices do not increase and small scale Kelvin-Helmholtz vortices are evident. In Fig.3a, a pair of coherent leading edge vortices emanating from leading edges of the wing planforms is clearly observed for all wing planforms. It is clear that vortex breakdowns occur after a certain distance from the lambda wing apex at different locations.

A symmetrical flow topology is present on both sides of chord axis for all wing planforms. Leading edge vortices maintain their coherent structure at $\alpha=10^{\circ}$ for all wings. However, the length of LEVs of
X-45 from wing apex is the smallest within the current planforms. Namely, unsteady flow occupies a great percentage of whole wing surface of X-45 for all cases of angle of attack, whereas well-defined LEVs are evident at relatively low angles of attack such as, $\alpha=7^{\circ}$ and $10^{\circ}$ for the delta and lambda wings. Fig 3b, variations of dimensionless locations $\left(\mathrm{L}_{\mathrm{vb}} / \mathrm{C}\right)$ of vortex breakdown with angle of attack for X-45 are depicted. A gradual attenuation is observed in Fig.3b. In other words, location of vortex breakdown moves to wing apex, when angle of attack is slightly increased. After $\alpha=20^{\circ}$, leading edge vortices break down in close region of wing apex. However, $\mathrm{L}_{\mathrm{vb}} / \mathrm{C}$ of X-45 takes very small values compared to delta wing. It can be concluded that modifications in delta wing planform affect location of vortex breakdown significantly.
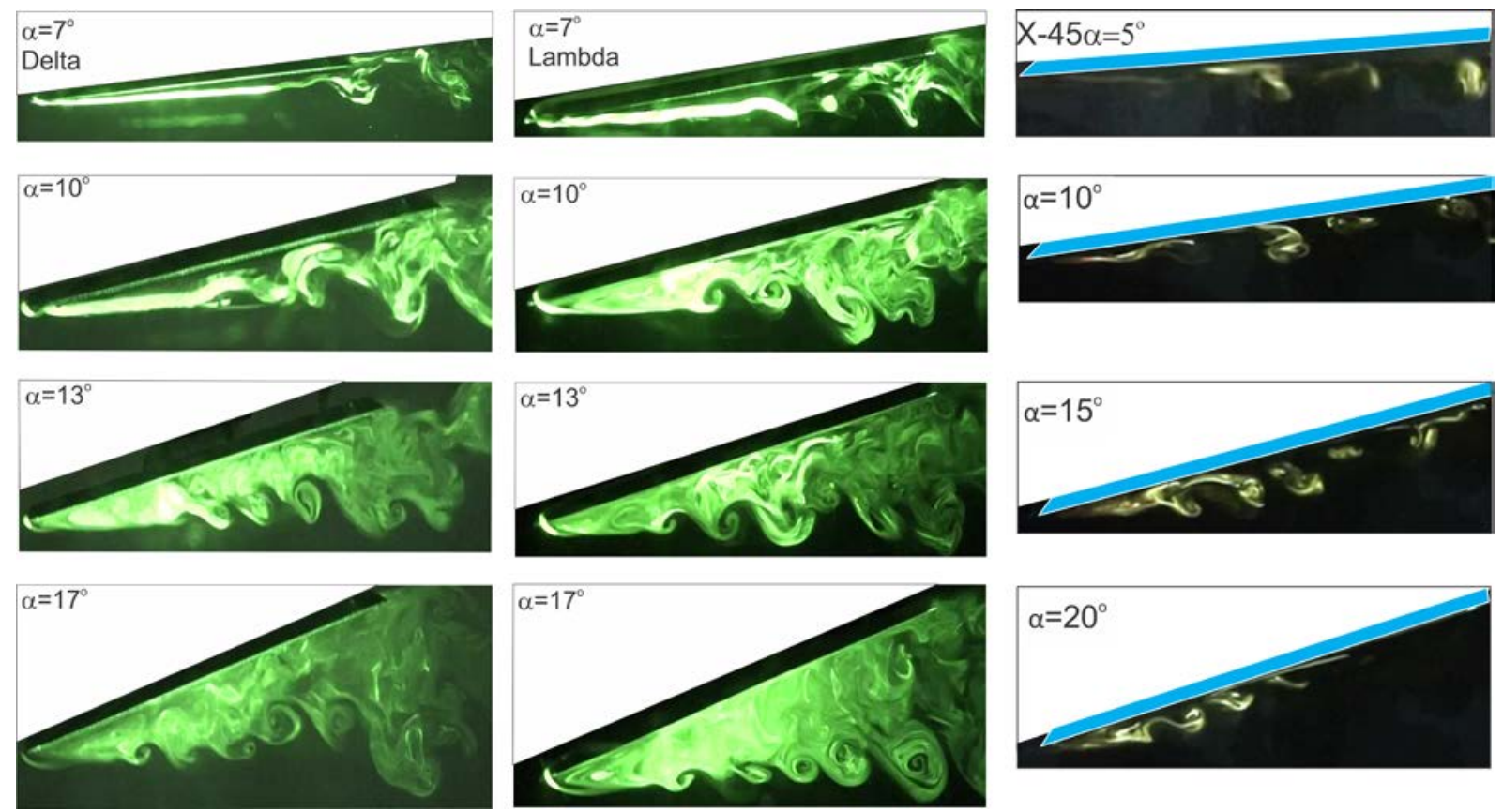

Fig.2a. Comparison of flow physics of delta, lambda and X-45 wing planforms using dye visualization within $5^{\circ} \leq \alpha \leq 20^{\circ}$ from side-view plane. Results of delta and lambda wings are adapted from [4] and [25], respectively.
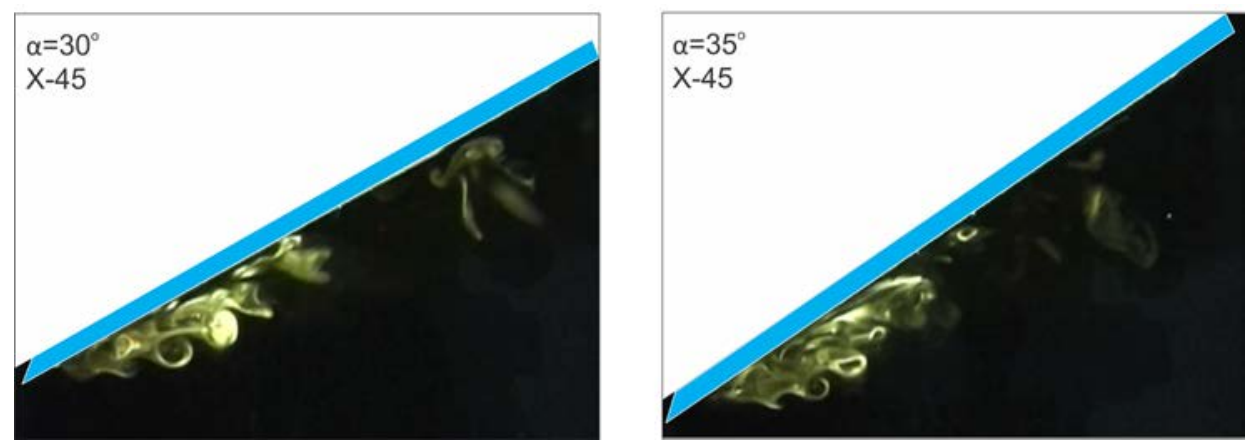

Fig.2b. Formation of leading edge vortices of X-45 wing under condition of high angle of attack $\alpha=30^{\circ}$ and $\alpha=35^{\circ}$ from side-view plane. 
Fig.4 presents the distribution of velocity vectors, $\langle\mathrm{V}\rangle$, which show that the velocity vectors have relatively high magnitude on both side of the mid-chord axis. However, velocity magnitudes along the leading edges become very small indicating the secondary vortices, which coincide with bifurcation lines present in corresponding streamline patterns, $\langle\Psi\rangle$. A symmetrical distribution of velocity vectors is clearly observed on both side of chord axis. The velocity vectors have relatively large magnitude in the central portion of delta and lambda wings. Moreover, the magnitude of velocity becomes relatively small farther outboard from the plane of symmetry.
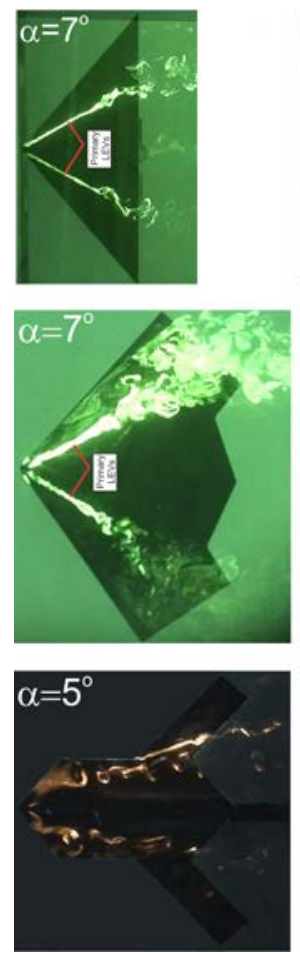
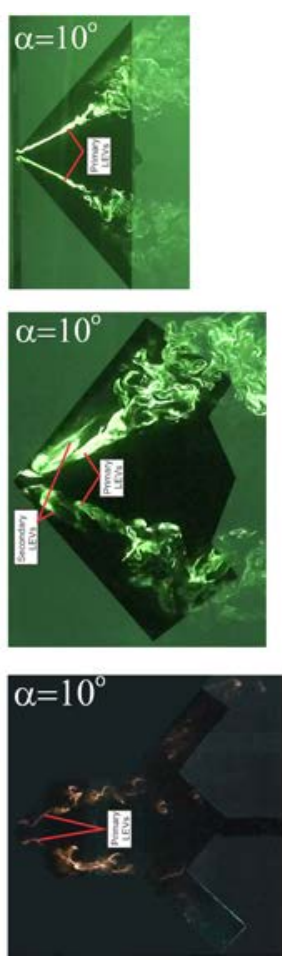

In contrast to delta and lambda planforms, velocity magnitudes have large magnitudes along the leading edge of X-45. As a result, the distance between lines of separation and reattachment of LEVs is smallest for X-45 compared to delta and lambda planforms. As the value of attack angle increases, the spatial extent of low velocity region increases. Furthermore, a welldefined swirl pattern of velocity is evident in the near region of the apex, except X-45. This swirl pattern gets larger, as $\alpha$ increases. As also seen in Fig. 3a, a low velocity region occupies the whole surface of the wing in the cases of high angle of attack.
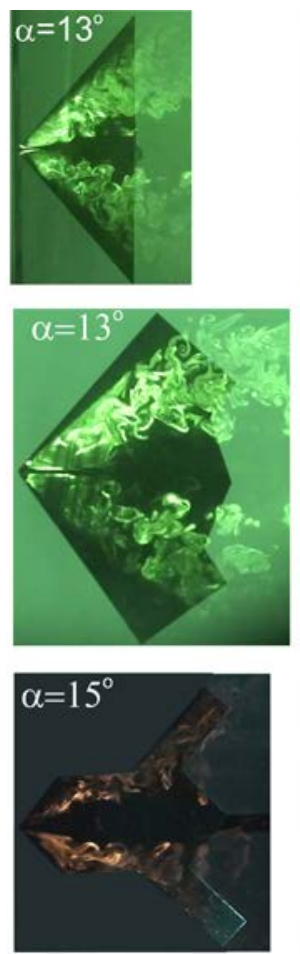
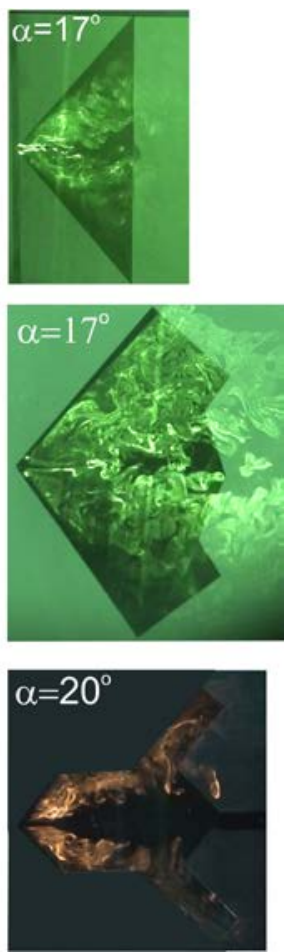

Fig. 3a. Formation and development of a leading edge vortex, the vortex breakdown and the separated flow region as a function of attack angle, $\alpha$. Results of delta and lambda wings are adapted from [4] and [25], respectively.

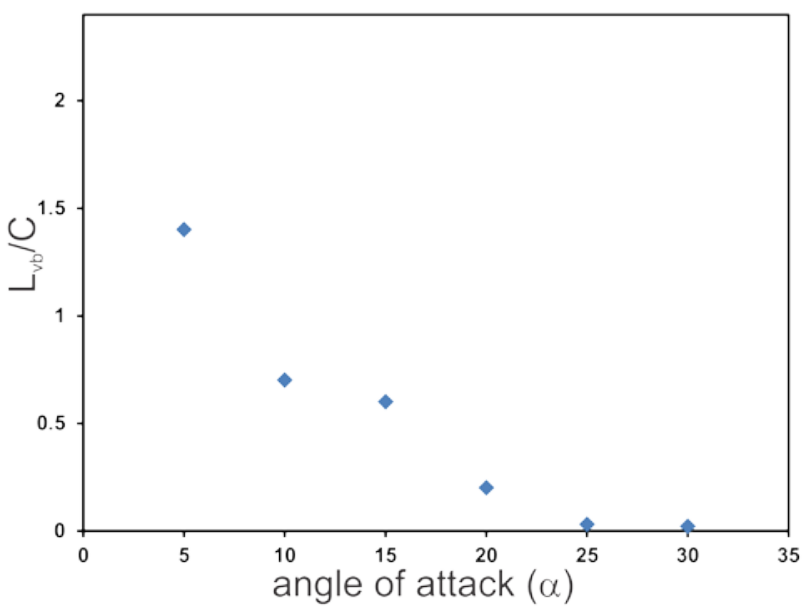

Fig. 3b. Variation of dimensionless location of the vortex breakdown $\left(\mathrm{L}_{\mathrm{vb}} / \mathrm{C}\right)$ with the angle of attack, $\alpha$ for $\mathrm{X}-45$ delta wing. 
Fig. 5 depicts variation of the time-averaged vorticity, $<\omega>$ with the angle of attack within $7^{\circ} \leq \alpha \leq 17^{\circ}$ for delta and lambda wings and $5^{\circ} \leq \alpha \leq 20^{\circ}$ for $\mathrm{X}-45$. In order to make direct comparison, patterns of the time-averaged vorticity, $\langle\omega\rangle$ have minimum and incremental values as $[<\omega>]_{\min }=0.4 \mathrm{~s}^{-1}$ and $\Delta[<\omega>]=1$ $\mathrm{s}^{-1}$, respectively. The contours of solid and dashed lines show the positive and negative contours,
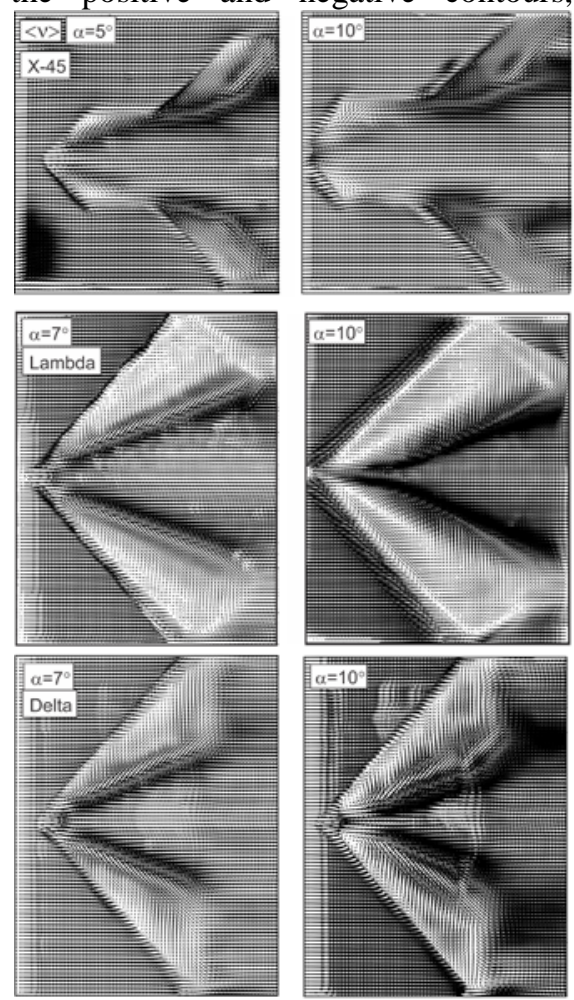

respectively. At first view, there is a pair of vortices which emanate from the leading edge of the wings and two well-defined clusters of negative and positive the time-averaged vorticity occur along the leading edges.
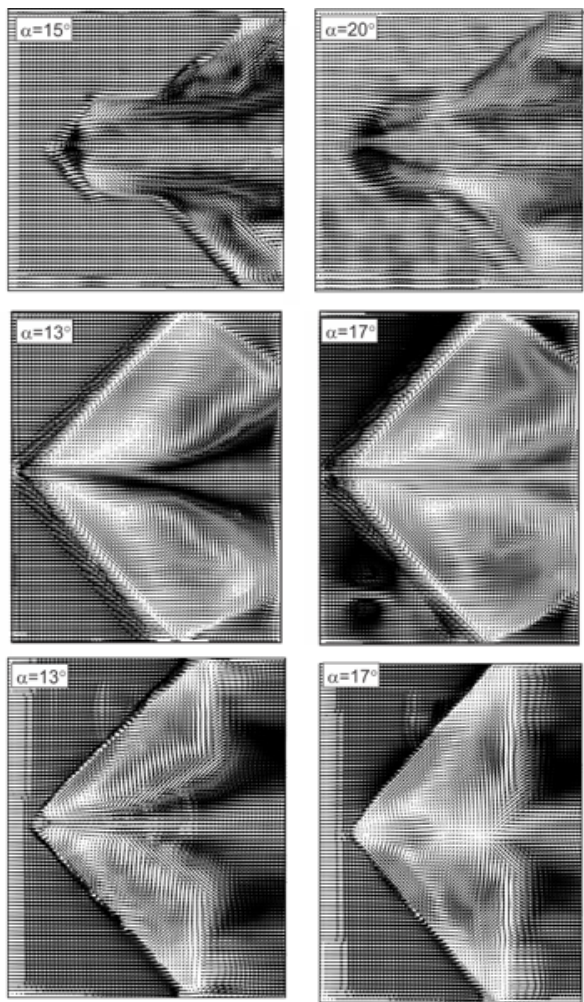

Fig 4. Patterns of the time-averaged velocity vectors, $<\mathrm{V}>$ as a function of attack angle, $\alpha$ for the delta, lambda and X-45 wings.
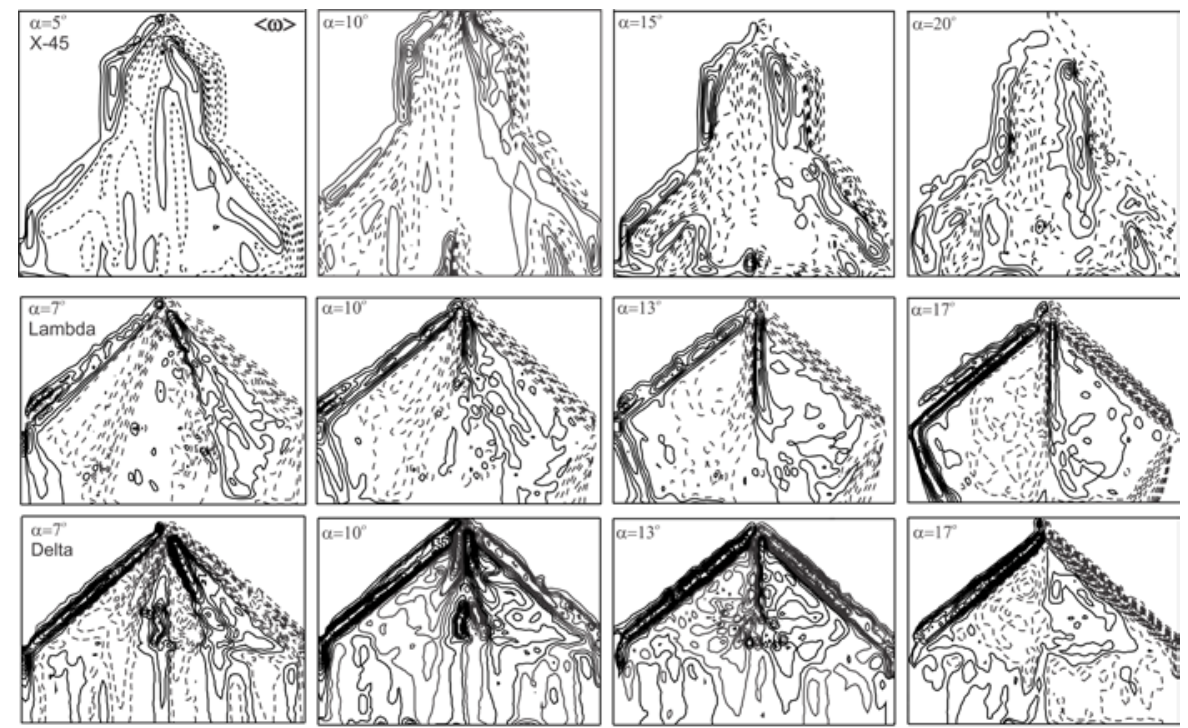

Fig. 5. Variation of the time-averaged vorticity, $\langle\omega\rangle$ of the wing planforms with the angle of attack, $\alpha$. Results of lambda wing are adapted from [25]. 
They occur due to the three dimensional instability of the shear layer separating from the surface of wings [2]. These vortices have an elongated form, which can be also understood from corresponding dye visualization experiments presented in Figure 3a. A

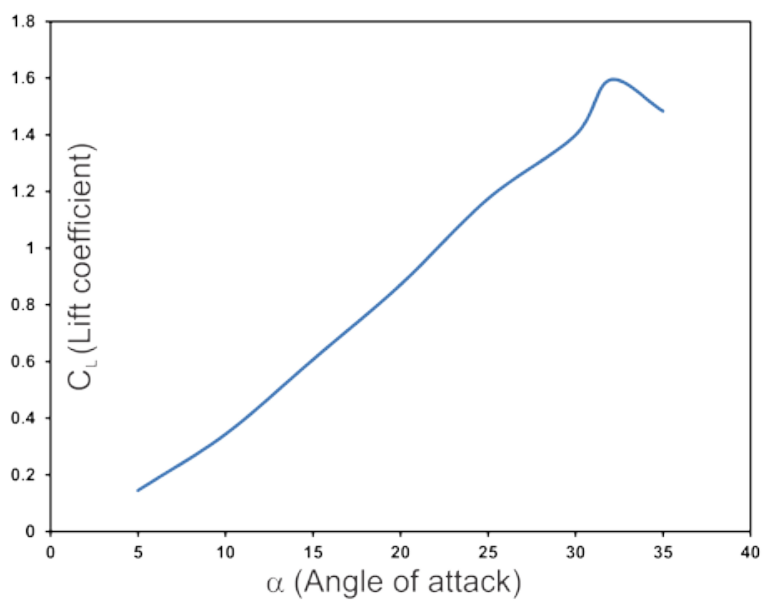

symmetrical flow topology dominates whole wing surface. Also, the peak points of the main leading edge vortices move downward towards the trailing edge as the angle of attack increases.

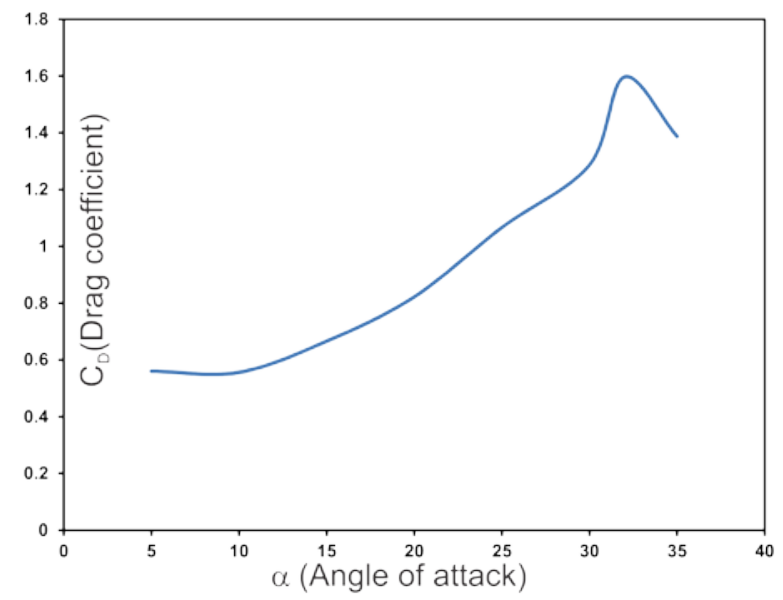

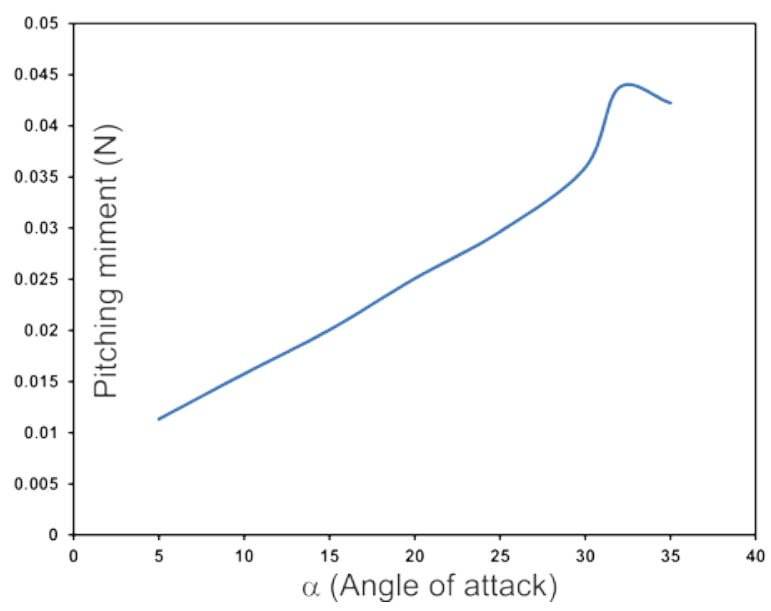

Fig. 6. Variations of aerodynamic coefficients and pitching moment of X-45 with the angle of attack, $\alpha$.

In Fig. 6, variation of aerodynamics coefficients with angle of attack are illustrated. The lift slope is small, on the order of 0.04 /degree, similar to the case of $\Lambda=60^{\circ}$ generic delta wing [26]. The stalling angle for $\mathrm{X}-45$ wing is $\alpha=32^{\circ}$, where the lift coefficient starts to decrease dramatically. Moreover, the lift coefficient increases with increasing sweep angle as reported by [1]. The stall occurs around $\alpha=25^{\circ}$ for generic delta wing with sweep angle of $\Lambda=45^{\circ}$.

Enhancement in stall angle is gained using $\mathrm{X}-45$ with sweep angle of $\Lambda=40^{\circ}$. As a result, modifications on a generic delta wing planform reveal a beneficial outcome for the missions requiring high angle of attack take-off and landing. Note that, the stalling angle of a generic delta wing with $\Lambda=60^{\circ}$ is $\alpha=35^{\circ}$, which is very close to that of $\mathrm{X}-45$. The drag coefficient initially maintains its magnitude, increases with similar slope with the lift coefficient until $\alpha=30^{\circ}$. At this angle of attack, there is a dramatic increase followed by a peak at $\alpha=32^{\circ}$, where stall occurs. Pitching moment characteristics of X-45 delta wing planform is similar to that of the lift coefficient with relatively large slope.

\section{CONCLUSIONS}

The current study aims at revealing the effects of angle of attack on the flow structure over delta wing planform named as X-45 using dye visualization and stereoscopic particle image velocimetry (stereo-PIV) techniques. In order to investigate aerodynamics characteristics, variations of lift, drag coefficients and pitching moment with angle of attack are plotted. Vortical flow over X-45 develop at very low angles of attack, and form close to the wing surface similar to 
delta and lambda planforms. A pair of well-defined LEVs is obviously identifiable at low angles of attack and they lose their coherency as the angle of attack increases.

High scale Kelvin-Helmholtz vortex structures could not occur at the bottom of the unstable flow region of X-45 compared to delta and lambda wing planforms. Increasing angle of attack father cannot increase vertical extent of unstable flow region of $\mathrm{X}$ 45 compared to high sweep delta wings. In contrast to delta and lambda planforms, velocity magnitudes have large magnitudes along the leading edge of $\mathrm{X}$ 45.

As a result, the distance between lines of separation and reattachment of LEVs is smallest for $\mathrm{X}-45$ compared to delta and lambda planforms. There is a pair of vortices which emanate from the leading edge of the wings and two well-defined clusters of negative and positive the time-averaged vorticity occur along the leading edges. The lift slope is small similar to the case of $\Lambda=60^{\circ}$ generic delta wing and stalling angle is occurred at $\alpha=32^{\circ}$ for $X-45$. In the light of this information, one can conclude that lift enhancement is achieved using X-45 type delta wing planform compared to generic delta wing.

\section{ACKNOWLEDGEMENTS}

The authors acknowledge the financial support of The Scientific and Technological Research Council of Turkey (TUBITAK) for funding under project No: 112M908. The Office of Scientific Research Projects of Osmaniye Korkut Ata University also provided the financial support for this Project under contract no: OKÜBAP-2014-PT3-038 and it is gratefully acknowledged.

\section{REFERENCES}

[1]. Gursul I., Gordinier R., and Visbal M. (2005). "Unsteady Aerodynamics of Nonslender Delta Wings” Progress in Aerospace Sciences Vol.41, pp.515-557.

[2]. Canpolat C., Yayla S., Sahin B., Akilli, H (2012). "Observation of the Vortical Flow over a Yawed Delta Wing”, Journal of Aerospace Engineering, Vol.25, pp. 613-626.

[3]. Yaniktepe, B., and Rockwell, D. (2004). "Flow Structure on a Delta Wing of Low Sweep Angle” AIAA Journal, Vol. 42, No. 3.

[4]. Canpolat C., Yayla, S., Sahin, B., and Akilli, H. (2009). "Dye Visualization of the Flow Structure over a Yawed Nonslender Delta Wing”, Journal of Aircraft, Vol. 46, No. 5.
[5]. Sahin B, Yayla S, Canpolat C, and Akilli H. (2012) "Flow structure over the yawed nonslender diamond wing", Aerospace Science and Technology, vol. 23, no. 1, pp. 108-119.

[6]. Cui, Y. D. , Lim T. T., Tsai H. M., (2007) "Control of Vortex Breakdown over a Delta Wing Using Forebody Slot Blowing”, AIAA Journal, Vol. 45, No. 1., pp. 110-117.

[7]. Menke, M., Yang, H., and Gursul, I., (1999). "Experiments on the Unsteady Nature of Vortex Breakdown over Delta Wings”, Experiments in Fluids, Vol. 27, pp. 262-272.

[8]. Yavuz, M., Elkhoury, M., and Rockwell, D. (2004). "Near-Surface Topology and Flow Structure on a Delta Wing", AIAA Journal, Vol. 42, No. 2, pp. 332-340.

[9]. Yaniktepe B, Ozalp C, Sahin B and Cag S, (2015a) "Experimental investigation of Surface Flow Structure over Non-Slender Diamond Wing”, 7th International Exergy, Energy and Environment Symposium, April 27-30, Valenciennes, France.

[10]. Yaniktepe B, Ozalp C, Sahin B and Cag S, (2015b) "Investigation Of Aerodynamic Characteristics and Flow Visualization Under Pitching Motion Over Non-Slender Delta Wing" International Congress On Engıneerıng And Natural Sciences May 15-19, Skopje, Makedonya.

[11]. Yaniktepe, B., and Rockwell, D. ( 2005). "Flow Structure on Diamond and Lambda Planforms:Trailing-Edge Region” AIAA Journal, Vol. 43, No. 7.

[12]. Elkhoury, M., Yavuz, M. M. and Rockwell, D., (2005). Near-Surface Topology of a Unmanned Combat Air Vehicles Planform: Reynolds Number Dependence. Journal of Aircraft, Vol. 42, No. 5, pp. 1318-1330.

[13]. Shim H.J., Park S.O. (2013). “ Low-speed windtunnel test results of a BWB-UCAV model”, Procedia Engineering, Vol.67, , pp.50-58.

[14]. McParlin, S, C., Bruce, R, J., Hepworth, A, G., Rae, A, J., (2006). "Low speed wind tunnel tests on the 1303 UCAV concept," 24th Applied Aerodynamics Conference, San Francisco, United States of America, AIAA 2006-2985.

[15]. Petterson, K., (2006). "Low speed aerodynamic and Flowfield characteristics of a UCAV," 24th Applied Aerodynamics Conference, San Francisco, United States of America, AIAA 2006-2986.

[16]. Woods M. I., Wood N. J. (2000). “Aerodynamic Characteristics of Lambda Wings", The Aeronautical Journal, Vol. 104, No.1034, pp. 165-174.

[17]. Pevitt C., Alam F. (2014). “ Static Computational Fluid Dynamics Simulations Around a Specialised Delta Wing”, Computer and Fluids, Vol.100, pp. 155-164. 
[18]. Prasad A. K. (2000). "Stereoscopic particle image velocimetry" Experimets in Fluids, Vol.29, No.2, pp.103-116.

[19]. Arroyo M.P., Greated C.A. (1991). "Stereoscopic Particle Image Velocimetry " Measurement Science \& Technology, Vol.2, No.12, pp.1181-1186.

[20]. Westerweel J. (1993). "Digital Particle Image Velocimetry, Theory and Application”, Delft University Press,.

[21]. Adrian R. J. (2005). "Twenty Years of Particle Image Velocimetry”, Experimental Fluids, Vol.39, pp.159-16.

[22]. Raffel M., Willert, C.E., Wereley, S.T., Kompenhans, J. (2007). "Particle Image Velocimetry: A Practical Guide” 2nd ed., Springer.

[23]. Ozgoren, M., Sahin, B., and Rockwell, D. (2002). "Vortex Structure on a Delta Wing at High Angle-of-Attack", AIAA Journal, Vol.40, No.2, pp.285-292.

[24]. Akilli, H., Sahin, B., and Rockwell, D. (2001). "Control of Vortex Breakdown by a Transversely-Oriented Wire", Physics of Fluids, Vol. 13, No. 2, pp. 452-463.

[25]. Yayla S., Canpolat C., Sahin B., Akilli H., (2013). "The effect of angle of attack on the flow structure over the nonslender lambda wing", Aerospace Science and Technology 28, 417-430.

[26]. Anderson J.D. Fundamentals of aerodynamics. McGraw-Hill Higher Education, ISBN 0-07-118146-6, 2001. 